\title{
Change in moderate alcohol consumption and quality of life: evidence from 2 population-based cohorts
}

\author{
Xiaoxin I. Yao PhD, Michael Y. Ni MD MPH, Felix Cheung PhD, Joseph T. Wu PhD, C. Mary Schooling PhD, \\ Gabriel M. Leung MD MPH, Herbert Pang PhD
}

Cite as: CMAJ 2019 July 8;191:E753-60. doi: 10.1503/cmaj.181583

\begin{abstract}
BACKGROUND: Although the association of moderate alcohol consumption with specific disorders, such as cardiovascular disease and cancers, has been well documented, the evidence of the broader impact of alcohol consumption on health-related quality of life is less clear. Our objective was to examine the association of drinking patterns with changes in physical and mental wellbeing across populations.
\end{abstract}

METHODS: We conducted a multilevel analysis with multivariate responses in the population-representative FAMILY Cohort in the Hong Kong Special Administrative Region, China, to examine the association between alcohol drinking patterns across 2 waves (2009-2013) (i.e., quitters, initiators, persistent drinkers, persistent former drinkers and lifetime abstainers) and changes in physical and mental well-being (Physical and Mental Component Summary of the 12-Item Short Form Health Survey [SF-12]). Analyses were stratified by sex. We validated findings using a nationally representative cohort in the United States, the National Epidemiologic Survey on Alcohol and Related Conditions (NESARC, 2001-2005).

RESULTS: In the FAMILY Cohort ( $n=$ 10386 ; median follow-up $2.3 \mathrm{yr}$ ), the change in mental well-being was more favourable in female quitters than in lifetime abstainers $(\beta=1.44,95 \%$ confidence interval $[\mathrm{Cl}] 0.43$ to 2.45 ; mean score change of +2.0 for quitters and +0.02 for lifetime abstainers). This association was validated in the NESARC ( $n=31079$; median follow-up $3.1 \mathrm{yr}$ ) ( $\beta=0.83,95 \% \mathrm{Cl} 0.08$ to 1.58 ; mean score change of -1.1 for quitters and -1.6 for lifetime abstainers).

INTERPRETATION: The change in mental well-being was more favourable in female quitters, approaching the level of mental well-being of lifetime abstainers within 4 years of quitting in both Chinese and American populations.

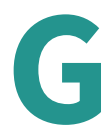

lobal alcohol consumption is rising and is the leading risk factor for the global burden of disease, and a major preventable risk factor of cardiovascular diseases, gastrointestinal diseases and neuropsychiatric disorders. ${ }^{1-4}$ However, the risks and benefits of moderate drinking are not clear. Cross-national studies have recommended the low-risk limit for alcohol consumption to be $100 \mathrm{~g}$ per week for both men and women, ${ }^{9}$ which is lower than the safe limits recommended by many countries, including Australia, Canada, Italy, Japan, Spain, the United Kingdom and the United States. ${ }^{10} \mathrm{~A}$ recent global study further challenged the idea that there is a safe limit. ${ }^{11,12}$ Indeed, alcoholic beverages have been classified as a Group 1 carcinogen by the International Agency for Research on Cancer. ${ }^{13}$ The examination of broader health outcomes related to alcohol consumption, such as health-related quality of life, may therefore be particularly valuable. However, few studies have investigated the impact of moderate drinking on health-related quality of life, and many have often relied on a single time-point measurement of alcohol consumption rather than longitudinal patterns of use. ${ }^{14,15} \mathrm{~A}$ randomized controlled trial (RCT) showed that initiating moderate drinking had no effect on quality of life. ${ }^{8}$ In a longitudinal study, reduced alcohol consumption over time was associated with better mental health-related quality of life. ${ }^{16}$

Validating associations across cohorts can improve causal inference by exploiting differences in confounding patterns between populations. ${ }^{17-21}$ Confounding patterns and social norms of alcohol consumption have been shown to differ, in that moderate drinkers in the US often have systematically healthier attributes than abstainers. ${ }^{22}$ In contrast, alcohol consumption is less normative among the Chinese population, and Chinese moderate drinkers have been shown to have less healthy attributes than abstainers..$^{20,23-26}$ 
We sought to examine the longitudinal relation between changes in drinking patterns and changes in physical and mental well-being in the Hong Kong Special Administrative Region, China. We further sought to externally validate our findings in a US population to clarify the relevance of the findings across populations.

\section{Methods}

\section{Study design and participants}

We selected large population-representative cohorts from Hong Kong (FAMILY Cohort) and the US (National Epidemiologic Survey on Alcohol and Related Conditions [NESARC]) to purposively leverage the differences in social norms. Consistent findings between these 2 distinct populations could provide evidence for the external validity for our associations. ${ }^{19,20}$ We derived the Hong Kong sample from Waves 1 and 2 of the FAMILY Cohort, which was conducted from 2009 to 2013 . The study design has been described in detail elsewhere. ${ }^{27}$ Participants were recruited based on stratified random sampling from all 18 districts in Hong Kong, with sample sizes proportionate to each of the district populations. For each district, we obtained a random sample of households based on a complete list of living quarters provided by the Census and Statistics Department in Hong Kong. All eligible household members residing in the sampled household were invited to participate. Participants were included if they were aged 18 years and older, were nondrinkers or moderate drinkers (on average $\leq 14$ drinks per week [196 g of pure alcohol] for men and $\leq 7$ drinks per week [98 g of pure alcohol] for women ${ }^{28}$ and completed both Waves 1 and 2. People who reported heavy drinking were excluded because the evidence for adverse impacts of heavy drinking on health-related quality of life is well established. ${ }^{29}$ The follow-up rate was $67.4 \%$ in the FAMILY Cohort.

For external validation, we used data from NESARC (20012005), a nationally representative survey of US citizens conducted by the National Institute on Alcohol Abuse and Alcoholism..$^{30,31}$ Similarly, stratified random sampling was conducted, and adults aged 18 years and older were interviewed face-to-face in household visits. The analytic sample was from the Waves 1 and 2 in 2001 to 2005, with the same inclusion criteria used in the FAMILY Cohort. The follow-up rate was $78.8 \%$ in the NESARC Cohort.

\section{Alcohol consumption patterns}

In both cohorts, alcohol measurements were available at 2 time points over a 4-year period. Lifetime abstainers were participants who reported that they never had a drink in their lifetime at both waves. Quitters during follow-up were participants who were current drinkers ( $\geq 1$ drink in the last 12 months) ${ }^{32}$ at Wave 1 and then quit drinking. Initiators during follow-up were nondrinkers (i.e., lifetime abstainers or former drinkers who had $\geq 1$ drink in their lifetime but not in the last 12 months ${ }^{32}$ who started drinking after Wave 1 . Persistent drinkers were participants who were current drinkers at both waves. Persistent former drinkers were participants who were former drinkers (including former heavy drinkers and former moderate drinkers) at Wave 1 who continued to not drink.

\section{Changes in physical and mental well-being}

Physical and mental well-being were measured by use of the 12-Item Short Form Health Survey (SF-12) version 2, which comprises the Physical Component Summary (PCS) and Mental Component Summary (MCS). ${ }^{33}$ The PCS and MCS scores were standardized by use of the mean and standard deviation (SD) of the US general population. ${ }^{33}$ Both scores range from 0 to 100 , with higher scores indicating better health. Outcomes of the current study are the changes in PCS and MCS between the 2 waves (i.e., score at Wave 2 subtracting score at Wave 1). Studies have shown that PCS and MCS scores are valid and reliable indicators of physical and mental health in a variety of population groups, including the Chinese and American general populations. ${ }^{34,35}$

\section{Statistical analysis}

We used multivariate multilevel models with random intercepts to examine the association between drinking patterns and changes in physical and mental well-being (i.e., 2 outcomes) simultaneously (Appendix 1, available at www.cmaj.ca/lookup/suppl/doi:10.1503/ cmaj.181583/-/DC1). Models were adjusted for potential confounders, including baseline sociodemographic measures (age, marital status, the highest level of education attained, occupation, monthly household income and ethnicity), body mass index (BMI) and smoking status. ${ }^{16,36,37}$ Models were then additionally adjusted for other potential confounders, including cardiovascular disease, gastrointestinal disease, liver disease, arthritis and mental disorders, because these could lead to abstaining from drinking and a decline in self-perceived health. ${ }^{16,36,38,39}$ We used the NESARC cohort to externally validate associations in the FAMILY Cohort. Lifetime abstainers were selected as the reference group, as abstainers constitute the largest proportion in the Chinese general population..$^{24,40-42}$ We did not include former drinkers in the reference group to avoid biased estimates from the inclusion of "sick quitters," as former drinkers are more likely to quit drinking because of illness. ${ }^{43-45}$ All analyses were stratified by sex because of differences in alcohol consumption patterns, sociodemographic factors and alcohol metabolism. ${ }^{15,36,46}$ Each 1 point difference in PCS and MCS scores could be interpreted as one-tenth of an SD, without the need for additional standardization of the $\beta$ coefficients. ${ }^{33}$ We conducted a sensitivity analysis with additional adjustment for physical activity (low, moderate and high, according to International Physical Activity Questionnaire). ${ }^{47,48}$ Another sensitivity analysis was conducted with adjustment for baseline sociodemographic measures only (without adjustment for BMI, smoking status, self-reported diseases and physical activity). We conducted a complete-case analysis, because the percentage of participants with at least 1 sociodemographic variable missing was only $5 \%$. Additional sensitivity analyses were carried out as detailed in the Supplementary Methods, available in Appendix 2, www.cmaj. ca/lookup/suppl/doi:10.1503/cmaj.181583/-/DC1. All analyses were done using $R$ version 3.4.0 and SAS version 9.4.

\section{Ethics approval}

The study was approved by the Institutional Review Board of the University of Hong Kong/Hospital Authority Hong Kong West Cluster, and written informed consent was obtained from participants before the surveys. 


\section{Results}

\section{FAMILY cohort}

The sample size was 10386 , after the exclusion of 41 participants with incomplete alcohol use patterns or outcomes. The mean age was 49.3 (SD 17.4) years, and the proportion of men was $44.2 \%$. The total follow-up time was 23055 person-years, with a median followup time of 2.3 years. In the FAMILY Cohort, $63.8 \%$ of men were nondrinkers (former drinkers and lifetime abstainers, $n=2931$ ) at Wave 1 . Of these, $74.8 \%$ remained lifetime abstainers at Wave 2, $20.9 \%$ started drinking and $4.3 \%$ were persistent former drinkers (Table $1 \mathrm{~A}$ and 1B). The remaining $36.2 \%$ were drinkers $(n=1661)$ at Wave 1 , of which $40.3 \%$ quit drinking during the follow-up period.

Most women were current nondrinkers at Wave 1 ( $n=5080$, $87.7 \%)$. Of these, most (89.8\%) remained lifetime abstainers at Wave $2,9.2 \%$ started drinking and $1.0 \%$ were persistent former drinkers (Table $1 \mathrm{~A}$ and $1 \mathrm{~B}$ ). Among drinkers ( $n=714,12.3 \%)$ at Wave $1,62.2 \%$ quit drinking during the follow-up period.

Men and women who were lifetime abstainers had the highest level of mental well-being at baseline, with mean mental health scores of 54.8 (SD 7.3) in men and 53.6 (SD 8.2) in women (Table $1 \mathrm{~A}$ and $1 \mathrm{~B}$ ). Persistent drinkers had the highest level of physical well-being at baseline.

\section{Drinking patterns and changes in physical and mental well-being}

Female quitters had a greater improvement in mental well-being relative to lifetime abstainers ( $\beta=1.44,95 \%$ confidence interval [CI] 0.43 to 2.45) (Table 2), which indicated that the change in mental well-being in female quitters was 1.44 points higher than that in female abstainers. Male persistent former drinkers had a greater improvement in mental well-being $(\beta=2.10,95 \% \mathrm{Cl} 0.30$ to 3.89) (Table 2), which indicated that the change in mental well-being in male persistent former drinkers was 2.10 points higher than that in male abstainers. Sensitivity analyses with different confounder adjustment showed consistent results (Appendix 2, Supplementary Table 1). Sensitivity analyses with multilevel multiple imputation and the exclusion of binge drinkers showed similar findings (results not shown).

\section{NESARC cohort: external validation}

In the NESARC cohort, the sample size was 31079 , after the exclusion of 286 participants with missing outcomes. The mean age was 46.3 (SD 17.5) years, and the proportion of men was $40.6 \%$. The total follow-up time was 94798 person-years, with a median follow-up time of 3.1 years. Baseline characteristics of the validation data in the NESARC cohort are shown in Appendix 2, Supplementary Table 2. Men and women who were lifetime abstainers had the highest level of mental well-being at baseline, with mean scores of 54.0 (SD 9.7) in men and 52.0 (SD 10.6) in women.

We externally validated associations detected in the FAMILY Cohort using the NESARC. Results were consistent in that female quitters had a more favourable change in mental well-being ( $\beta=$ $0.83,95 \% \mathrm{Cl} 0.08$ to 1.58 in model $1 ; \beta=0.83,95 \% \mathrm{Cl} 0.07$ to 1.58 in model 2). However, the association between male persistent former drinkers and change in mental well-being was not validated $(p>0.05)$. Analyses were repeated with inverse probability weighting and poststratification weighting in both cohorts, which yielded similar findings (results not shown). We also reverted the use of both samples by conducting the primary analysis with the NESARC cohort and the external validation with the FAMILY Cohort, which led to the same validated findings. The mean scores of mental wellbeing among female quitters and lifetime abstainers at Waves 1 and 2 are shown in Appendix 2, Supplementary Table 3. In the FAMILY Cohort, female quitters had a greater increase of the score than lifetime abstainers, with a mean score change of +2.0 for quitters and +0.02 for lifetime abstainers; in the NESARC cohort, female quitters showed a smaller decline in mental well-being, with a mean score change of -1.1 for quitters and -1.6 for lifetime abstainers.

\section{Interpretation}

We found that lifetime alcohol abstainers reported the highest level of mental well-being. Women who quit drinking were found to have a greater improvement in mental well-being than lifetime abstainers. This association was found in a Hong Kong cohort as well as in a US cohort. On average, the mental well-being of female quitters approached the level of lifetime abstainers within a 4-year period in both cohorts (median 2.3 years of follow-up in the FAMILY Cohort and 3.1 years in the NESARC cohort). In contrast, initiation and persistent moderate drinking for 4 years were not associated with better mental or physical well-being. These results remained consistent after adjustment for sociodemographic characteristics, BMI, smoking status, self-reported diseases and physical activity.

Interventional studies supporting the positive impact of alcohol cessation on mental well-being have been mostly based on individuals with alcohol dependence; ${ }^{49-51}$ evidence for the positive effect of brief alcohol interventions for people who drink moderately is emerging. ${ }^{52}$ Cross-sectional studies have suggested a positive association between moderate drinking and mental wellbeing. ${ }^{53,54}$ However, our findings are consistent with those of a previous smaller longitudinal study that showed alcohol reduction to be associated with better mental well-being and an RCT that showed no effect of moderate drinking on quality of life. ${ }^{8,16}$ Crossnational studies have also challenged the idea that moderate drinking could have health benefits. ${ }^{9,11,12}$ We found that quitting alcohol was associated with a more favourable change in mental well-being among women. The explanation for our findings and the underlying mechanism are not clear. It is possible that alcoholrelated neurotoxicity reverses following abstinence. ${ }^{55-57}$ Alcohol cessation may also reduce stressful life events, such as conflict within family, difficulties in employment and legal troubles, resulting in improved mental well-being. ${ }^{58,59}$ It is also possible that improved mental well-being may result from the psychological benefits of "giving up" per se rather than an effect of alcohol, as most Chinese women in Hong Kong use alcohol fewer than 4 times per month, which may not have a physiologic effect. ${ }^{60}$

\section{Limitations}

Our study is subject to the following limitations. First, prospective cohort studies are susceptible to selection bias and attrition bias. The FAMILY Cohort enrolled complete households in which all adult 
Table 1A: Baseline characteristics of men in the FAMILY Cohort, by alcohol use pattern ( $n=4592)$

\section{Characteristic}

Alcohol consumption at Wave $1, \mathrm{~g} / \mathrm{wk}$

Age, $\mathrm{yr}$

Marital status

Never married

Married/living with someone as if married

Widowed

Divorced/separated

Education level

Primary/elementary

Secondary/high school

Tertiary nondegree

Tertiary degree or higher

Household monthly income, HK\$

$<10000$

10 000-19999

20 000-39 999

$\geq 40000$

Employment status

Employed

Unemployed

Economically inactive

BMI

Smoking status

Current

Former

Never

Self-reported conditions

Cardiovascular disease

Stomach and intestinal disease

Liver disease

Arthritis

Mental disorder

Physical health score ${ }^{\star \star}$

Mental health score $\dagger$

No. $(\%)$ of men or mean \pm SD

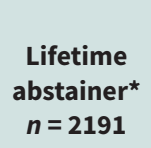

0.0

$51.2 \pm 18.6$

$n=2190 \ddagger \ddagger$

$547(25.0)$

$1529(69.8)$

$47(2.1)$

67 (3.1)

$n=2176 \ddagger \ddagger$

603 (27.7)

955 (43.9)

332 (15.3)

286 (13.1)

$n=2077 \ddagger$

709 (34.1)

$592(28.5)$

$556(26.8)$

220 (10.6)

$n=2187 \ddagger$

1237 (56.6)

$50(2.3)$

$900(41.2)$

$23.9 \pm 3.9$

$n=2162 \ddagger$

360 (16.7)

$133(6.2)$

$1669(77.2)$

\section{Quitter during \\ follow-upt \\ $n=670$}

$24.1 \pm 34.9$

$47.3 \pm 17.5$

153 (7.0)

41 (1.9)

45 (2.1)

70 (3.2)

49 (2.2)

$49.1 \pm 8.0$

$54.8 \pm 7.3$

$30(4.5)$
196 (29.3)

447 (66.7)

8 (1.2)

19 (2.8)

$n=668 \ddagger \ddagger$

148 (22.2)

331 (49.6)

101 (15.1)

88 (13.2)

$n=658 \ddagger \ddagger$

178 (27.1)

193 (29.3)

200 (30.4)

$87(13.2)$

459 (68.5)

$29(4.3)$

$182(27.2)$

$24.1 \pm 3.8$

$n=661 \ddagger$

177 (26.8)

101 (15.3)

$383(57.9)$

Initiator
during
follow-upł
$n=613$

$48.3 \pm 17.3$

172 (28.1)

412 (67.2)

$n=610 \ddagger \ddagger$

152 (24.9)

291 (47.7)

$n=578 \ddagger \ddagger$

189 (32.7)

398 (64.9)

200 (32.6)

$151(25.0)$

404 (66.9)

$18(2.7)$

$14(2.1)$

21 (3.1)

$5(0.7)$

$50.3 \pm 7.1$

$53.7 \pm 7.8$
0.0

9 (1.5)

20 (3.3)

83 (13.6)

84 (13.8)

170 (29.4)

$150(26.0)$

69 (11.9)

15 (2.4)

$24.2 \pm 3.7$

$n=604 \ddagger \ddagger$

49 (8.1)

\section{Persistent \\ drinker§ \\ $n=991$}

$39.5 \pm 45.0$

$46.6 \pm 15.1$

$n=989 \ddagger \ddagger$

227 (23.0)

724 (73.2)

11 (1.1)

27 (2.7)

$n=989 \ddagger \ddagger$

235 (23.8)

502 (50.8)

139 (14.1)

113 (11.4)

$n=963 \ddagger \ddagger$

203 (21.1)

302 (31.4)

314 (32.6)

144 (15.0)

755 (76.2)

23 (2.3)

$213(21.5)$

$24.2 \pm 3.4$

$n=971 \neq \ddagger$

374 (38.5)

120 (12.4)

477 (49.1)

25 (4.1)

25 (2.5)

21 (2.1)

22 (2.2)

43 (4.3)

9 (0.9)

$50.8 \pm 6.2$

$54.2 \pm 7.3$

$54.4 \pm 6.6$
Persistent former drinker $n=127$

0.0

$65.5 \pm 15.4$

14 (11.0)

96 (75.6)

12 (9.4)

$5(3.9)$

$73(57.5)$

42 (33.1)

$6(4.7)$

6 (4.7)

$n=124 \ddagger \ddagger$

73 (58.9)

29 (23.4)

14 (11.3)

8 (6.5)

$n=126 \ddagger \ddagger$

$33(26.2)$

3 (2.4)

90 (71.4)

$24.3 \pm 3.6$

$n=124 \ddagger \ddagger$

$30(24.2)$

$67(54.0)$

27 (21.8)

30 (23.6)

7 (5.5)

7 (5.5)

$10(7.9)$

8 (6.3)

$43.3 \pm 10.9$

$52.4 \pm 10.1$

Note: $\mathrm{BMI}=$ body mass index, $\mathrm{HK} \$=$ Hong Kong dollar, $\mathrm{SD}=$ standard deviation.

${ }^{*}$ Never had a drink at both Waves 1 and 2 .

tCurrent drinkers at Wave 1 and then quit drinking between Waves 1 and 2.

‡Nondrinkers (i.e., former drinkers or lifetime abstainers) at Wave 1 but started drinking between Waves 1 and 2 .

$\S$ Current drinkers at both Waves 1 and 2 .

IFormer drinkers at Wave 1 and continued to not drink during the follow-up.

**Physical Component Summary of the 12-Item Short Form Health Survey.

††Mental Component Summary of the 12-Item Short Form Health Survey.

$\ddagger \ddagger$ Denominators are different owing to varying percentages of missing data. The percentage of participants with at least 1 sociodemographic variable missing was $5 \%$. 
Table 1B: Baseline characteristics of women in the FAMILY Cohort, by alcohol use pattern $(n=5794)$

\begin{tabular}{|c|c|c|c|c|c|}
\hline \multirow[b]{2}{*}{ Characteristic } & \multicolumn{5}{|c|}{ No. $(\%)$ of women or mean \pm SD } \\
\hline & $\begin{array}{l}\text { Lifetime } \\
\text { abstainer* } \\
n=4563\end{array}$ & $\begin{array}{l}\text { Quitter during } \\
\text { follow-up } \dagger \\
n=444\end{array}$ & $\begin{array}{c}\text { Initiator } \\
\text { during } \\
\text { follow-upł } \\
n=466\end{array}$ & $\begin{array}{c}\text { Persistent } \\
\text { drinker§ } \\
n=270\end{array}$ & $\begin{array}{c}\text { Persistent } \\
\text { former } \\
\text { drinkerף } \\
n=51\end{array}$ \\
\hline Alcohol consumption at Wave $1, \mathrm{~g} / \mathrm{w}$ & 0.0 & $13.1 \pm 16.8$ & 0.0 & $17.7 \pm 18.9$ & 0.0 \\
\hline Age, yr & $50.6 \pm 16.9$ & $41.8 \pm 15.6$ & $44.8 \pm 16.8$ & $41.7 \pm 14.8$ & $58.2 \pm 19.3$ \\
\hline Marital status & $n=4546 \ddagger \ddagger$ & $n=443 \ddagger \ddagger$ & & $n=269 \ddagger \ddagger$ & \\
\hline Never married & $791(17.4)$ & $139(31.4)$ & $135(29.0)$ & $99(36.8)$ & $8(15.7)$ \\
\hline Married/living with someone as if married & $2999(66.0)$ & $243(54.9)$ & 279 (59.9) & $129(48.0)$ & $27(52.9)$ \\
\hline Widowed & $517(11.4)$ & $26(5.9)$ & $29(6.2)$ & $16(5.9)$ & $13(25.5)$ \\
\hline Divorced/separated & $239(5.3)$ & $35(7.9)$ & $23(4.9)$ & $25(9.3)$ & $3(5.9)$ \\
\hline Education levels & $n=4542 \ddagger \ddagger$ & $n=441 \ddagger \ddagger$ & $n=463 \ddagger \ddagger$ & $n=266 \ddagger \ddagger$ & \\
\hline Primary/elementary & $1698(37.4)$ & $99(22.4)$ & $107(23.1)$ & $59(22.2)$ & $27(52.9)$ \\
\hline Secondary/high school & $2021(44.5)$ & $192(43.5)$ & $228(49.2)$ & $121(45.5)$ & $20(39.2)$ \\
\hline Tertiary nondegree & $445(9.8)$ & $69(15.6)$ & $66(14.3)$ & $40(15.0)$ & $1(2.0)$ \\
\hline Tertiary degree or higher & $378(8.3)$ & $81(18.4)$ & $62(13.4)$ & $46(17.3)$ & $3(5.9)$ \\
\hline Household monthly income, HK\$ & $n=4328 \ddagger \ddagger$ & $n=436 \ddagger \ddagger$ & $n=443 \ddagger \ddagger$ & $n=262 \ddagger \ddagger$ & \\
\hline$<10000$ & $1625(37.5)$ & $111(25.5)$ & $139(31.4)$ & $65(24.8)$ & $27(52.9)$ \\
\hline $10000-19999$ & $1198(27.7)$ & $121(27.8)$ & $128(28.9)$ & $64(24.4)$ & $13(25.5)$ \\
\hline $20000-39999$ & $1112(25.7)$ & $121(27.8)$ & $114(25.7)$ & $82(31.3)$ & $7(13.7)$ \\
\hline$\geq 40000$ & $393(9.1)$ & $83(19.0)$ & $62(14.0)$ & $51(19.5)$ & $4(7.8)$ \\
\hline Employment status & $n=4551 \ddagger \ddagger$ & & & $n=268 \ddagger \ddagger$ & \\
\hline Employed & $1937(42.6)$ & $260(58.6)$ & $247(53.0)$ & $172(64.2)$ & $14(27.5)$ \\
\hline Unemployed & $79(1.7)$ & $13(2.9)$ & $8(1.7)$ & $7(2.6)$ & $1(2.0)$ \\
\hline Economically inactive & $2535(55.7)$ & $171(38.5)$ & $211(45.3)$ & $89(33.2)$ & $36(70.6)$ \\
\hline BMI & $23.6 \pm 3.9$ & $22.7 \pm 3.8$ & $23.2 \pm 4.2$ & $23.0 \pm 4.2$ & $24.3 \pm 4.3$ \\
\hline Smoking status & $n=4561 \ddagger \ddagger$ & $n=443 \ddagger \ddagger$ & $n=465 \ddagger \ddagger$ & $n=267 \ddagger \ddagger$ & \\
\hline Current & $128(2.8)$ & $42(9.5)$ & $30(6.5)$ & $40(15.0)$ & $11(21.6)$ \\
\hline Former & $31(0.7)$ & $23(5.2)$ & $10(2.2)$ & $21(7.9)$ & $11(21.6)$ \\
\hline Never & $4402(96.5)$ & $378(85.3)$ & $425(91.4)$ & $206(77.2)$ & $29(56.9)$ \\
\hline \multicolumn{6}{|l|}{ Self-reported conditions } \\
\hline Cardiovascular disease & $204(4.5)$ & $13(2.9)$ & $14(3.0)$ & $4(1.5)$ & $8(15.7)$ \\
\hline Stomach and intestinal disease & $117(2.6)$ & $11(2.5)$ & $11(2.4)$ & $12(4.4)$ & $3(5.9)$ \\
\hline Liver disease & $79(1.7)$ & $8(1.8)$ & $5(1.1)$ & $5(1.9)$ & $2(3.9)$ \\
\hline Arthritis & $263(5.8)$ & $23(5.2)$ & $22(4.7)$ & $16(5.9)$ & $10(19.6)$ \\
\hline Mental disorder & $139(3.0)$ & $14(3.2)$ & $13(2.8)$ & $10(3.7)$ & $5(9.8)$ \\
\hline Physical health score ${ }^{\star \star}$ & $47.5 \pm 8.7$ & 49. \pm 7.3 & $49.3 \pm 7.7$ & $50.2 \pm 6.6$ & $41.3 \pm 12.7$ \\
\hline Mental health score $\dagger$ & $53.6 \pm 8.2$ & $50.9 \pm 8.7$ & $52.9 \pm 7.5$ & $50.8 \pm 9.3$ & $51.0 \pm 9.5$ \\
\hline \multicolumn{6}{|c|}{ 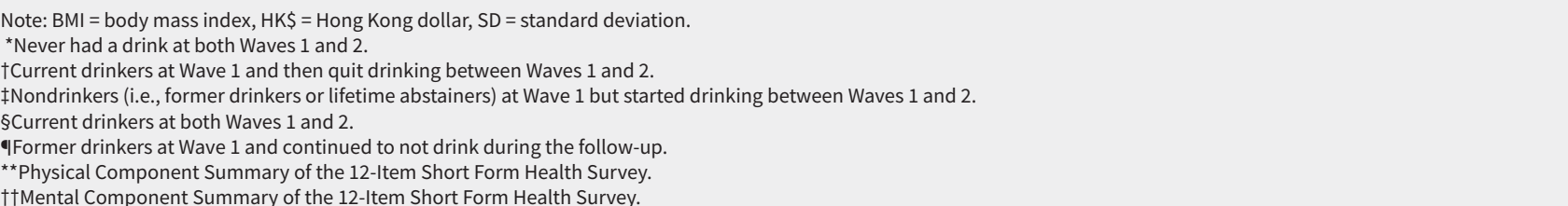 } \\
\hline
\end{tabular}


Table 2: Alcohol use patterns and changes in physical and mental well-being between Waves 1 and 2 in the FAMILY Cohort

$\beta$-coefficient ( $95 \%$ confidence interval)*

\begin{tabular}{|c|c|c|c|c|c|c|c|c|c|}
\hline \multirow{2}{*}{$\begin{array}{l}\text { Group; } \\
\text { model }\end{array}$} & \multirow{2}{*}{$\begin{array}{l}\text { Lifetime } \\
\text { abstainert }\end{array}$} & \multicolumn{2}{|c|}{ Quitter during follow-upł } & \multicolumn{2}{|c|}{ Initiator during follow-up§ } & \multicolumn{2}{|c|}{ Persistent drinkerף } & \multicolumn{2}{|c|}{ Persistent former drinker** } \\
\hline & & $\triangle \mathrm{PCS}$ & $\triangle M C S$ & $\triangle \mathrm{PCS}$ & $\Delta$ MCS & $\triangle \mathrm{PCS}$ & $\triangle \mathrm{MCS}$ & $\triangle \mathrm{PCS}$ & $\triangle \mathrm{MCS}$ \\
\hline \multicolumn{10}{|l|}{ Men } \\
\hline Model $1 \mathrm{t}^{\dagger}$ & Ref. & $\begin{array}{c}0.42 \\
(-0.29 \text { to } 1.13)\end{array}$ & $\begin{array}{c}0.17 \\
(-0.68 \text { to } 1.01)\end{array}$ & $\begin{array}{c}0.51 \\
(-0.23 \text { to } 1.25)\end{array}$ & $\begin{array}{c}0.68 \\
(-0.19 \text { to } 1.56)\end{array}$ & $\begin{array}{c}0.38 \\
(-0.25 \text { to } 1.02)\end{array}$ & $\begin{array}{c}0.13 \\
(-0.63 \text { to } 0.89)\end{array}$ & $\begin{array}{c}0.11 \\
(-1.40 \text { to } 1.63)\end{array}$ & $\begin{array}{c}2.10 \\
\text { (0.30 to } 3.89)\end{array}$ \\
\hline Model 2ł‡ & Ref. & $\begin{array}{c}0.4 \\
(-0.31 \text { to } 1.11)\end{array}$ & $\begin{array}{c}0.21 \\
(-0.63 \text { to } 1.06)\end{array}$ & $\begin{array}{c}0.53 \\
(-0.21 \text { to } 1.26)\end{array}$ & $\begin{array}{c}0.68 \\
(-0.19 \text { to } 1.56)\end{array}$ & $\begin{array}{c}0.34 \\
(-0.30 \text { to } 0.97)\end{array}$ & $\begin{array}{c}0.13 \\
(-0.63 \text { to } 0.89)\end{array}$ & $\begin{array}{c}0.13 \\
(-1.39 \text { to } 1.65)\end{array}$ & $\begin{array}{c}2.08 \\
(0.28 \text { to } 3.89)\end{array}$ \\
\hline \multicolumn{10}{|l|}{ Women } \\
\hline Model $1 \dagger \dagger$ & Ref. & $\begin{array}{c}-0.06 \\
(-1.01 \text { to } 0.88)\end{array}$ & $\begin{array}{c}1.44 \\
\text { (0.43 to } 2.45)\end{array}$ & $\begin{array}{c}-0.07 \\
(-1.00 \text { to } 0.86)\end{array}$ & $\begin{array}{c}0.2 \\
(-0.80 \text { to } 1.20)\end{array}$ & $\begin{array}{c}-0.59 \\
(-1.81 \text { to } 0.64)\end{array}$ & $\begin{array}{c}0.84 \\
(-0.48 \text { to } 2.16)\end{array}$ & $\begin{array}{c}-0.01 \\
(-2.68 \text { to } 2.66)\end{array}$ & $\begin{array}{c}-0.65 \\
(-3.51 \text { to } 2.21)\end{array}$ \\
\hline Model 2ł‡ & Ref. & $\begin{array}{c}-0.09 \\
(-1.03 \text { to } 0.85)\end{array}$ & $\begin{array}{c}1.42 \\
\text { (0.41 to } 2.43)\end{array}$ & $\begin{array}{c}-0.07 \\
(-1.00 \text { to } 0.85)\end{array}$ & $\begin{array}{c}0.2 \\
(-0.80 \text { to } 1.20)\end{array}$ & $\begin{array}{c}-0.69 \\
(-1.91 \text { to } 0.54)\end{array}$ & $\begin{array}{c}0.79 \\
(-0.53 \text { to } 2.10)\end{array}$ & $\begin{array}{c}-0.27 \\
(-2.94 \text { to } 2.40)\end{array}$ & $\begin{array}{c}-0.80 \\
(-3.67 \text { to } 2.06)\end{array}$ \\
\hline 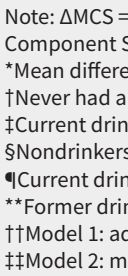 & $\begin{array}{l}\text { the change in } m \\
\text { ummary of the } \\
\text { nce in Physical } \\
\text { drink at both Wa } \\
\text { kers at Wave } 1 \text { ar } \\
\text { (i.e., former drir } \\
\text { kers at both Wav } \\
\text { kers at Wave } 1 \text { a } \\
\text { justed for age, } m\end{array}$ & $\begin{array}{l}\text { ental health score ( } \\
\text { 2-Item Short Form } \\
\text { omponent Summar } \\
\text { ves } 1 \text { and } 2 \text {. } \\
\text { d then quit drinking } \\
\text { kers or lifetime abst } \\
\text { es } 1 \text { and } 2 \text {. } \\
\text { nd continued to not }\end{array}$ & $\begin{array}{l}\text { Mental Component } \\
\text { Health Survey), Ref. } \\
\text { ry and Mental Comp } \\
\text { g between Waves } 1 \text { a } \\
\text { tainers) at Wave } 1 \text { bu } \\
\text { drink during the fol } \\
\text { ducation levels, mo }\end{array}$ & $\begin{array}{l}\text { Summary of the } 12-1 \\
=\text { reference categor } \\
\text { onent Summary sco } \\
\text { and } 2 \text {. } \\
\text { ut started drinking b } \\
\text { llow-up. } \\
\text { onthly household inc }\end{array}$ & $\begin{array}{l}\text {-Item Short Form } \mathrm{He} \\
\text { ry. } \\
\text { ore between the alc } \\
\text { between Waves } 1 \text { an } \\
\end{array}$ & $\begin{array}{l}\text { ealth Survey), } \triangle \mathrm{PCS} \\
\text { ohol consumption } \\
\text { ad } 2 \text {. }\end{array}$ & category and the ref & ference category. & \\
\hline
\end{tabular}

members agreed to participate, thus potentially selecting betterfunctioning family units. However, the "healthy volunteer effect" could still have occurred if individuals were sampled instead. ${ }^{27}$ The application of censoring weights in both cohorts did not appreciably alter results, suggesting that attrition had little influence on our results. Second, as alcohol consumption pattern was self-reported, underreporting and some degree of misclassification are possible, which should be considered when interpreting the findings. ${ }^{44}$ Current drinkers may claim to be nondrinkers because of social desirability bias. ${ }^{36}$ However, the Cohen's $w$ effect size for differences in alcohol consumption between high and low social desirability groups was small in our study. ${ }^{61,62}$ Further, there has been a shift in the social norms of alcohol consumption and increased societal acceptance of social drinking among Hong Kong Chinese. ${ }^{60,63}$ Misclassification of former drinkers as lifetime abstainers has been documented in previous studies. ${ }^{64,65}$ In the FAMILY Cohort, 9.6\% of the women who reported never having a drink at Wave 2 had reported drinking at or before Wave 1 , which is substantially lower than in other cohorts and surveys in the US and UK. ${ }^{64,65}$ Third, the relatively short period of follow-up does not allow for capturing the dynamic tracks of drinking patterns and health status across the entire life course. ${ }^{15}$ However, we believe the finding of this study may inform future prospective studies with longer follow-up. Fourth, whether there is a sex difference in the link between alcohol use patterns and mental well-being remains unclear, and assessment of such a difference would require interaction analyses and larger samples. ${ }^{66}$ Fifth, missing data must be considered; however, the application of multilevel multiple imputation yielded similar findings, suggesting that the missing data had little influence on our findings.

\section{Conclusion}

Our findings, that lifetime alcohol abstainers report the highest level of mental well-being and quitting alcohol improves mental well-being among women, suggest caution in recommending that moderate drinking could improve health-related quality of life. ${ }^{37,67}$ Instead, quitting drinking may be associated with a more favourable change in mental well-being, approaching the level of lifetime abstainers. This may be analogous to smoking cessation, which results in the recovery of health outcomes to the level of lifetime nonsmokers. ${ }^{68-70}$ Global alcohol consumption is expected to continue to increase unless effective strategies are employed. ${ }^{1,71}$ Further studies are needed to establish clearly the impact of alcohol use on mental and physical well-being before alcohol is recommended as part of a healthy lifestyle.

\section{References}

1. Global status report on alcohol and health 2018. Geneva: World Health Organization; 2018.

2. Global health risks: mortality and burden of disease attributable to selected major risks. Geneva: World Health Organization; 2009.

3. Rehm J, Baliunas D, Borges GL, et al. The relation between different dimensions of alcohol consumption and burden of disease: an overview. Addiction 2010;105:817-43.

4. Corrao G, Bagnardi V, Zambon A, et al. A meta-analysis of alcohol consumption and the risk of 15 diseases. Prev Med 2004;38:613-9.

5. Millwood IY, Walters RG, Mei XW, et al. Conventional and genetic evidence on alcohol and vascular disease aetiology: a prospective study of 500000 men and women in China. Lancet 2019;393:1831-42.

6. Room R, Babor T, Rehm J. Alcohol and public health. Lancet 2005;365:519-30.

7. Goldberg IJ, Mosca L, Piano MR, et al. AHA Science Advisory: Wine and your heart: a science advisory for healthcare professionals from the Nutrition Committee, Council on Epidemiology and Prevention, and Council on Cardiovascular Nursing of the American Heart Association. Circulation 2001;103:472-5. 
8. Gepner Y, Golan R, Harman-Boehm I, et al. Effects of initiating moderate alcohol intake on cardiometabolic risk in adults with type 2 diabetes: a 2-year randomized, controlled trial. Ann Intern Med 2015;163:569-79.

9. Wood AM, Kaptoge S, Butterworth AS, et al. Risk thresholds for alcohol consumption: combined analysis of individual-participant data for 599912 current drinkers in 83 prospective studies. Lancet 2018;391:1513-23.

10. Kalinowski A, Humphreys K. Governmental standard drink definitions and lowrisk alcohol consumption guidelines in 37 countries. Addiction 2016;111:1293-8.

11. GBD 2016 Alcohol Collaborators. Alcohol use and burden for 195 countries and territories, 1990-2016: a systematic analysis for the Global Burden of Disease Study 2016. Lancet 2018;392:1015-35.

12. Burton R, Sheron N. No level of alcohol consumption improves health. Lancet 2018;392:987-8.

13. IARC Working Group on the Evaluation of Carcinogenic Risks to Humans. Alcohol consumption and ethyl carbamate. IARC Monogr Eval Carcinog Risks Hum 2010; 96:3-1383.

14. Roerecke M, Rehm J. Alcohol consumption, drinking patterns, and ischemic heart disease: a narrative review of meta-analyses and a systematic review and meta-analysis of the impact of heavy drinking occasions on risk for moderate drinkers. BMC Med 2014;12:182.

15. Britton A, Ben-Shlomo Y, Benzeval M, et al. Life course trajectories of alcohol consumption in the United Kingdom using longitudinal data from nine cohort studies. BMC Med 2015;13:47.

16. Bell S, Britton A. An exploration of the dynamic longitudinal relationship between mental health and alcohol consumption: a prospective cohort study. BMC Med 2014;12:91.

17. Smithers LG, Kramer MS, Lynch JW. Effects of breastfeeding on obesity and intelligence: causal insights from different study designs. JAMA Pediatr 2015; 169:707-8.

18. Belfort MB, Rifas-Shiman SL, Kleinman KP, et al. Infant feeding and childhood cognition at ages 3 and 7 years: effects of breastfeeding duration and exclusivity. JAMA Pediatr 2013;167:836-44.

19. Brion MJ, Lawlor DA, Matijasevich A, et al. What are the causal effects of breastfeeding on IQ, obesity and blood pressure? Evidence from comparing highincome with middle-income cohorts. Int J Epidemiol 2011;40:670-80.

20. Au Yeung SL, Schooling CM. More ways to distinguish real from artefactual associations in observational studies [letter]. Int J Epidemiol 2014;43:1665-6.

21. Ni MY, Jiang C, Cheng KK, et al. Stress across the life course and depression in a rapidly developing population: the Guangzhou Biobank Cohort Study. Int J Geriatr Psychiatry 2016;31:629-37.

22. Naimi TS, Brown DW, Brewer RD, et al. Cardiovascular risk factors and confounders among nondrinking and moderate-drinking US adults. Am J Prev Med 2005; 28:369-73.

23. Global status report on alcohol and health 2014. Geneva: World Health Organization; 2014

24. Li Y, Jiang $\mathrm{Y}$, Zhang M, et al. Drinking behaviour among men and women in China: the 2007 China Chronic Disease and Risk Factor Surveillance. Addiction 2011;106:1946-56.

25. Results from the 2007 National Survey on Drug Use and Health: national findings (Office of Applied Studies, NSDUH Series H-34, DHHS Publication No. SMA 08-4343). Rockville (MD): Substance Abuse and Mental Health Services Administration; 2008.

26. Au Yeung SL, Jiang CQ, Zhang WS, et al. Systematic differences among never, occasional and moderate alcohol users in southern China, and its use in alcohol research: a cross-sectional study. J Epidemiol Community Health 2013;67:1054-60.

27. Leung GM, Ni MY, Wong PT, et al. Cohort profile: FAMILY Cohort. Int J Epidemiol 2017;46:e1.

28. 2015-2020 Dietary guidelines for Americans. 8th edition. Washington (D.C.): US Department of Health and Human Services and US Department of Agriculture; 2015.

29. Foster JH, Powell JE, Marshall EJ, et al. Quality of life in alcohol-dependent subjects - a review. Qual Life Res 1999;8:255-61.

30. Grant BF, Kaplan KD, Shepard J, et al. Source and accuracy statement for Wave 1 of the 2001-2002 National Epidemiologic Survey on Alcohol and Related Conditions. Bethesda (MD): National Institute on Alcohol Abuse and Alcoholism; 2003.

31. Grant BF, Kaplan KD. Source and accuracy statement for the 2004-2005 Wave 2 National Epidemiologic Survey on Alcohol and Related Conditions. Bethesda (MD): National Institute on Alcohol Abuse and Alcoholism; 2005.

32. Chen CM, Yi H, Dawson DA, et al. Alcohol use and alcohol use disorders in the United States, a 3-year follow-up: main findings from the 2004-2005 Wave 2 National Epidemiologic Survey on Alcohol and Related Conditions (NESARC). Bethesda (MD): National Institute on Alcohol Abuse and Alcoholism; 2010

33. Ware JE Jr, Kosinski M, Turner-Bowker DM, et al. User's manual for the SF-12v2 ${ }^{\circledR}$ Health Survey (with a supplement documenting SF-12 ${ }^{\circledR}$ Health Survey). Lincoln (RI): QualityMetric Incorporated; 2002.
34. Gandek B, Ware JE, Aaronson NK, et al. Cross-validation of item selection and scoring for the SF-12 Health Survey in nine countries: results from the IQOLA Project. International Quality of Life Assessment. J Clin Epidemiol 1998;51:1171-8.

35. Lam ET, Lam CL, Fong DY, et al. Is the SF-12 version 2 Health Survey a valid and equivalent substitute for the SF-36 version 2 Health Survey for the Chinese? J Eval Clin Pract 2013;19:200-8.

36. Bergmann MM, Rehm J, Klipstein-Grobusch K, et al. The association of pattern of lifetime alcohol use and cause of death in the European prospective investigation into cancer and nutrition (EPIC) study. Int J Epidemiol 2013;42:1772-90.

37. Schrieks IC, Wei MY, Rimm EB, et al. Bidirectional associations between alcoho consumption and health-related quality of life amongst young and middle-aged women. J Intern Med 2016;279:376-87.

38. Shaper AG, Wannamethee G, Walker M. Alcohol and mortality in British men: explaining the U-shaped curve. Lancet 1988;2:1267-73.

39. Fillmore KM, Stockwell T, Chikritzhs T, et al. Moderate alcohol use and reduced mortality risk: systematic error in prospective studies and new hypotheses. Ann Epidemiol 2007;17(Suppl):S16-23.

40. Janghorbani M, Ho SY, Lam TH, et al. Prevalence and correlates of alcohol use: a population-based study in Hong Kong. Addiction 2003;98:215-24.

41. Statistics on behavioural risk factors: alcohol consumption. Hong Kong: Centre for Health Protection, Department of Health, the Government of the Hong Kong Special Administrative Region; 2009. Available: www.chp.gov.hk/en/statistics/ data/10/280/390.html (accessed 2018 May 20).

42. Tang YL, Xiang XJ, Wang XY, et al. Alcohol and alcohol-related harm in China: policy changes needed. Bull World Health Organ 2013;91:270-6.

43. Roerecke M, Rehm J. Ischemic heart disease mortality and morbidity rates in former drinkers: a meta-analysis. Am J Epidemiol 2011;173:245-58.

44. Poikolainen K, Vartiainen E, Korhonen HJ. Alcohol intake and subjective health. Am J Epidemiol 1996;144:346-50.

45. Green CA, Polen MR. The health and health behaviors of people who do not drink alcohol. Am J Prev Med 2001;21:298-305.

46. Mumenthaler MS, Taylor JL, O'Hara R, et al. Gender differences in moderate drinking effects. Alcohol Res Health 1999;23:55-64

47. Craig CL, Marshall AL, Sjostrom M, et al. International physical activity questionnaire: 12-country reliability and validity. Med Sci Sports Exerc 2003;35:1381-95.

48. Lee PH, Yu YY, McDowell I, et al. Performance of the international physical activity questionnaire (short form) in subgroups of the Hong Kong chinese population. Int J Behav Nutr Phys Act 2011;8:81.

49. Weisner CM, Chi FW, Lu Y, et al. Examination of the effects of an intervention aiming to link patients receiving addiction treatment with health care: the LINKAGE clinical trial. JAMA Psychiatry 2016;73:804-14.

50. Frischknecht U, Sabo T, Mann K. Improved drinking behaviour improves quality of life: a follow-up in alcohol-dependent subjects 7 years after treatment. Alcohol Alcohol 2013;48:579-84.

51. Martinotti G, Di Nicola M, Janiri L. Efficacy and safety of aripiprazole in alcohol dependence. Am J Drug Alcohol Abuse 2007;33:393-401.

52. Freyer-Adam J, Baumann S, Haberecht K, et al. Can brief alcohol interventions in general hospital inpatients improve mental and general health over 2 years? Results from a randomized controlled trial. Psychol Med 2018;Sep 4:1-9.

53. Chan AM, von Muhlen D, Kritz-Silverstein D, et al. Regular alcohol consumption is associated with increasing quality of life and mood in older men and women: the Rancho Bernardo Study. Maturitas 2009;62:294-300.

54. Stranges S, Notaro J, Freudenheim JL, et al. Alcohol drinking pattern and subjective health in a population-based study. Addiction 2006;101:1265-76.

55. Topiwala A, Allan CL, Valkanova V, et al. Moderate alcohol consumption as risk factor for adverse brain outcomes and cognitive decline: longitudinal cohort study. BMJ 2017;357:j2353.

56. Carlen PL, Wortzman G, Holgate RC, et al. Reversible cerebral atrophy in recently abstinent chronic alcoholics measured by computed tomography scans. Science 1978;200:1076-8.

57. Muuronen A, Bergman H, Hindmarsh T, et al. Influence of improved drinking habits on brain atrophy and cognitive performance in alcoholic patients: a 5-year follow-up study. Alcohol Clin Exp Res 1989;13:137-41.

58. Boden JM, Fergusson DM. Alcohol and depression. Addiction 2011;106:906-14.

59. Conner KR. Clarifying the relationship between alcohol and depression. Addiction 2011;106:915-6.

60. Alcohol and health: Hong Kong situation. Hong Kong: Centre for Health Protection, Department of Health, the Government of the Hong Kong Special Administrative Region; 2011. Available: www.dh.gov.hk/english/pub_rec/pub_rec_ar/pdf/ncd ap2/action_plan_2_alcohol\%20and\%20health\%20HK\%20situation_e.pdf (accessed 2018 Aug. 20).

61. Crowne DP, Marlowe D. A new scale of social desirability independent of psychopathology. J Consult Psychol 1960;24:349-54.

62. Cohen J. Statistical power analysis for the behavioral sciences. 2nd ed. Hillsdale (NJ): Lawrence Erlbaum Associates; 1988 
63. Wong EC, Kim JH, Goggins WB, et al. Chinese women's drinking patterns before and after the Hong Kong alcohol policy changes. Alcohol Alcohol 2018;53:477-86.

64. Caldwell TM, Rodgers B, Power C, et al. Drinking histories of self-identified lifetime abstainers and occasional drinkers: findings from the 1958 British Birth Cohort Study. Alcohol Alcohol 2006;41:650-4.

65. Knott CS, Coombs N, Stamatakis E, et al. All-cause mortality and the case for age specific alcohol consumption guidelines: pooled analyses of up to 10 population based cohorts. BMJ 2015;350:h384.

66. Nieuwenhuis S, Forstmann BU, Wagenmakers EJ. Erroneous analyses of interactions in neuroscience: a problem of significance. Nat Neurosci 2011; 14:1105-7.

67. Dyer O. $\$ 100 \mathrm{~m}$ alcohol study is cancelled amid pro-industry “bias." BMJ 2018; 361:k2689.

68. Jha P, Ramasundarahettige C, Landsman V, et al. 21st-century hazards of smoking and benefits of cessation in the United States. N Engl J Med 2013; 368:341-50.

69. Cully M. Public health: the benefits and challenges of smoking cessation. Nat Rev Cardiol 2013;10:117.

70. Xu T, Holzapfel C, Dong X, et al. Effects of smoking and smoking cessation on human serum metabolite profile: results from the KORA cohort study. BMC Med 2013;11:60.

71. Manthey J, Shield KD, Rylett M, et al. Global alcohol exposure between 1990 and 2017 and forecasts until 2030: a modelling study. Lancet 2019 May 7. pii: S0140-6736(18)32744-2.

Competing interests: None declared.

This article has been peer reviewed.

Affiliations: School of Public Health, Li Ka Shing Faculty of Medicine (Yao, Ni, Cheung, Wu, Schooling, Leung, Pang), and The State Key Laboratory of Brain and Cognitive Sciences (Ni), The University of Hong Kong, Hong Kong Special Administrative Region, China; Graduate School of Public Health and Health Policy (Schooling), City University of New York, New York, NY

Contributors: Xiaoxin Yao, Michael Ni, Gabriel Leung and Herbert Pang conceived the study and planned the analyses. Xiaoxin Yao, Michael Ni and Herbert Pang carried out the study and drafted the manuscript. Xiaoxin Yao and Herbert Pang analyzed the data. All authors contributed to the interpretation of the data and revision of the paper. All authors gave final approval of the version to be published and agreed to be accountable for all aspects of the work.

Funding: The Hong Kong Jockey Club Charities Trust was the sole funder of the FAMILY Project from 2007 to 2014. The funding source had no role in the design of the study; the collection, analysis or interpretation of the data; the writing of the manuscript; or the decision to submit the manuscript for publication.

Data sharing: The data that support the findings of this study are archived at the School of Public Health, The University of Hong Kong. The FAMILY Cohort is set up as a supported-access resource; an application is required to access the data. Further information is available at https://familycohort.sph.hku.hk/en/data_access. The data for the National Epidemiologic Survey on Alcohol and Related Conditions (NESARC) cohort is available through the National Institute on Alcohol Abuse and Alcoholism.

Acknowledgements: The authors are most grateful for the participants' support in the FAMILY Cohort and the NESARC cohort. NESARC is funded by the National Institute on Alcohol Abuse and Alcoholism, with supplemental support from the National Institute on Drug Abuse. The authors thank Tiffany Leung for her help with the manuscript formatting.

Accepted: June 1, 2019

Correspondence to: Michael Ni, nimy@hku.hk 